\title{
围晊对翻阳湖洪水位的影响及防治对策
}

\author{
窦鸿身 ${ }^{1}$ 闵 骞 ${ }^{2}$ 史复祥 $^{1}$ \\ (1: 中国科学院南京地理与湖泊㼋究所, 南京 $210008 ; 2$ : 江西省都昌蒸发站, 都昌 332600 )
}

\begin{abstract}
提 要略述了翻阳湖围圼的简要历史和现状,分析了近 50 年来洪水位的演变趋势, 指出 围星使鄱阳湖面积和容积缩小, 调蓄功能衰退, 以致水情不断恶化, 洪峰水位逐渐上升, 高水位的 出现顿率明显加大, 致灾洪水越来越频繁. 在此基础上,将围室对洪水位的影响进行了分析计算, 得出了各典型年洪水在不同围晊背景下的围星效应值.
\end{abstract}

关链词 鄱阳湖 围晊 洪涝灾害 对策
分类号
5422

鄱阳湖古称彭齔泽,地处长江中游之南岸, 江西省辖境之北部, 为我国面积最大的淡水湖 泊.它上纳韸江、抚河、信江、饶河和修水五大河流,形成一个完整的鄱阳湖水系, 流域面积达 $16.2 \times 10^{4} \mathrm{~km}^{2}$, 多年平均入湖径流量 $1457 \times 10^{8} \mathrm{~m}^{3}$. 上游来水经湖盆调蓄后, 由北部的湖口沲 入长江. 鄱阳湖为一吞吐型的过水性湖泊, 当水位达 $21.69 \mathrm{~m}$ 时, 南北长 $170 \mathrm{~km}$, 东西最大湖宽 $74 \mathrm{~km}$, 平均宽 $20.4 \mathrm{~km}$, 水域面积 $2933 \mathrm{~km}^{2}$, 最大水深 $29.19 \mathrm{~m}$, 平均水深 $5.1 \mathrm{~m}$, 蓄水量 $150.1 \times$ $10^{8} \mathrm{~m}^{3}$. 由于该湖具有巨大的调蓄功能, 对湖区以及长江中下游广大地区的防洪减灾等方面发 挥着显著的水利效益.

但是,鄱阳湖又是一个滩地资源十分丰富的湖泊.围旺是鄱阳湖滩地资源开发利用的主要 方式. 由于围是是一种封闭式的开发利用 ${ }^{[1]}$, 是人与湖争地的经济活动, 因而便与湖泊水利之 间产生了尖锐的矛盾。

\section{1 围旺的简要历史及现状}

鄱阳湖区以星殖湖滩洲地为目的筑堤建圩活动, 大致在宋代才逐渐兴起, 及至明、清时期, 湖区筑堤建圩活动有了迅速发展，湖滩地的围星进入盛期 ${ }^{[2]}$. 民国时期, 湖区围星活动有增无 减, 到建国前夕, 环湖共建有大小圩子 363 座, 圩区总面积 $15.8 \times 10^{4} \mathrm{hm}^{2}$, 受益农田 $10.54 \times$ $10^{4} \mathrm{hm}^{2}$, 圩堤总长度 $1391.1 \mathrm{~km}$. 彼时圩区堤防低矮单薄, 堤高一般仅 $2.5 \mathrm{~m}$ 左右, 且每座圩子 的规模也较小, 堤线长而零乱, 抗洪能力低下, 在遭遇 1931 年的特大洪水之后, 湖区堤防几乎 全部溃决, 湖区群众深受洪港灾害之苦.

建国后,鄱阳湖区的围星进入了一个新的时期,无论是围旺的速度或规模,都是过去任何 历史时期所无可比拟的. 据分析, 1949 年以来, 围厔大致经历了四个阶段的变化过程(图 1).

第一阶段 (50 年代): 建国初期, 湖区接连遭受 1949、1954 年两次大的洪水灾害, 大小坶堤 大部溃决, 圩区满目疮痍. 为了恢复生产, 重建家园, 湖区群众致力于修堤堵口, 加固堤防, 联圩

" 中国科学院基础研究特别支持项目“人类活动对湖沼系统影响与对策研究”贷助.

收稿日期: 1998-10-10.突鸿身, 男, 1936 年生, 研究员。 
并垸, 将一些分散零乱的小圩逐渐联并成大圩, 在 进行联圩的过程中将原诸小圩间分布散乱的湖滩 地扩并入联圩之内. 同时, 又新建成了乐丰、饶丰、 成新、军山湖等围控区.

第二阶段 (60 年代): 这一时期, 在“以粮为 纲”的“极左”思潮方针指导下, 湖区掀起了“向湖 滩地要粮”、“与水争地”的热潮, 是鄱阳湖围星的 高潮时期, 建圩的数量最多, 围是面积最大, 湖区 一些著名的大圩多在这一时期兴建. 如位于湖区 东南部的康山圩于 1966 年动员 10 万群众兴建, 圩区面积 $343.4 \mathrm{~km}^{2}$, 圩堤长 $34 \mathrm{~km}$, 圩内有 8 个乡

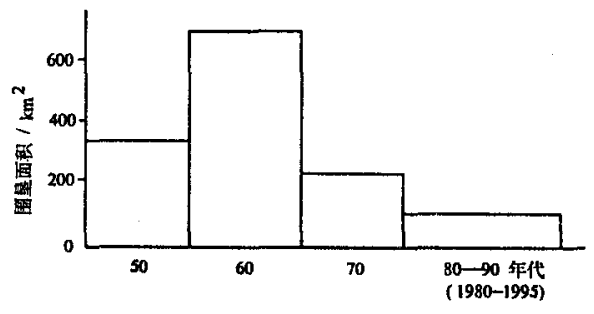

图 1 翻阳湖区不同年代围星面积比较

Fig. 1 Comparison of reclaimed areas in certain times, Poyang Lake district

镇和 1 个国营综合是殖场, 面积之大, 在长江中下游其它湖区也属罕见. 此外, 面积在 $20 \mathrm{~km}^{2}$ 以上的大圩还有恒湖、信丰、朱港等圩.

第三阶段 (70 年代): 继 50、60 年代的大规模围圼之后, 湖区水情已显著恶化, 洪涝灾害日 益加剧, 宣目围是之害已逐渐被人们所认识, 因此围圼的速度明显下降, 围圼的面积和建圩数 量显著减少. 这一时期除围控的珠湖圩面积达 $80.8 \mathrm{~km}^{2}$ 和莲北圩面积达 $35.5 \mathrm{~km}^{2}$ 之外,一般 都是些小扞, 面积多在 $1-3 \mathrm{~km}^{2}$.

第四阶段(1980-1995 年):80 年代, 湖区大规模建圩活动已基本得到控制, 无新的圩子兴 建. 但是, 随着水利建设的发展和联圩并垸工程的进一步实施,通过联圩并垸仍有小面积的湖 滩地被圈围于联圩之内. 如珠湖圩原于 70 年代兴建, 后于 1986 年与利池圩联并, 改称珠湖联 圩,通过此次联圩工程使利池湖、大否湖以西和大否湖下游约 $8 \mathrm{~km}^{2}$ 的滩地被围是.

鄱阳湖滩地是钉螺的㻑生区, 为灭杀钉螺, 于 90 年代在部分滩地实施血防旺殖, 先后建成 浆潭圩、莲西圩等, 使部分洲滩被围旺.

以上各阶段总计,自建国以来鄱阳湖区共围控湖泊总面积 $1466.9 \mathrm{~km}^{2[3]}$.

\section{9 年以来洪水的演变趋势}

鄱阳湖警戒水位为 $19 \mathrm{~m}$. 从表 1 中可以大致看出鄱阳湖近 50 年来洪水位的演变趋势, 主 要体现在: (1)年最高水位旺明显的上升趋势, 表明䧽阳湖洪水位在逐渐上升. (2)年最高水位 超过警戒水位 $1 \mathrm{~m} 、 2 \mathrm{~m}$ 的频率显著增多,说明鄱阳湖致灾洪水越来越频繁.

表 1 都昌站不同年代最高水位、不同级别水位出现年数及出现频率 $P(\%) *$

Tab.1 The maximum flood levels, frequencies and prababilities of various peak floods at Duchang station

\begin{tabular}{cccccccc}
\hline 年 $\mathbb{E}$ & $\bar{H}_{\text {max }} / \mathrm{m}$ & $M_{19}$ & $M_{20}$ & $M_{21}$ & $P\left\{19 \leqslant \bar{H}_{\max }<20\right\}$ & $P\left\{20 \leqslant \bar{H}_{\max }<21\right\}$ & $P\left\{\bar{H}_{\max } \geqslant 21\right\}$ \\
\hline $1950-1959$ & 18.51 & 2 & 1 & 1 & $35.0 \%$ & $10.0 \%$ & $1.5 \%$ \\
$1960-1969$ & 18.38 & 4 & 2 & 0 & $36.5 \%$ & $12.5 \%$ & $2.0 \%$ \\
$1970-1979$ & 18.93 & 6 & 2 & 0 & $37.2 \%$ & $14.7 \%$ & $2.0 \%$ \\
$1980-1989$ & 19.10 & 5 & 2 & 1 & $40.6 \%$ & $18.0 \%$ & $3.0 \%$ \\
$1990-1997$ & 20.19 & 8 & 4 & 2 & $49.0 \%$ & $24.0 \%$ & $6.5 \%$ \\
\hline
\end{tabular}

$* \bar{H}_{\mathrm{mxx}}$ 为年最高水位相对冻结基面的多年平均值 $(\mathrm{m}) ; M_{19}, M_{20}, M_{21}$ 为年最高水位超过 $19 \mathrm{~m}, 20 \mathrm{~m}, 21 \mathrm{~m}$ 的年数. 
从 $1988-1998$ 年的最近 11 年都昌站实际观测资料看, 每年的最高水位都在 $19 \mathrm{~m}$ 以上, 这是过去任何时期都不曾出现过的.年最高水位超过 $20 \mathrm{~m}$ 的情况, 在 1992-1998 年的 7 年内 就有 5 年, 分别是 1992 年的 $20.58 \mathrm{~m} 、 1993$ 年的 $20.18 \mathrm{~m} 、 1995$ 年的 $21.78 \mathrm{~m} 、 1996$ 年的 $21.02 \mathrm{~m}$ 和 1998 年的 $22.42 \mathrm{~m}$ (湖口站水位为 $22.58 \mathrm{~m}$ ), 比历史上任何时段都更频繁. 年最高水 位超过 21 的情况, 从 1948-1998 年的 51 年内共出现了 5 次, 其中有 3 次就出现在 90 年代, 而从 50-70 年代长达 30 年的时段内仅出现过 1 次 (1954 年), 另一次出现在 80 年代 (1983 年). 90 年代, 鄱阳湖水情恶化到如此程度,这也是过去任何历史时段都不曾发生的.

以上这些现象均突出地表明鄱阳湖高水位的出现频率明显加大, 重现期显著缩短.

从都昌水位站 1950 年以来年最高水位变化曲线 ${ }^{[4]}$ 可以看出, 鄱阳湖洪水位呈波浪形上升 之势态. 据分析计算, 其多年平均上升速度为 $0.023 \mathrm{~m} \cdot \mathrm{a}^{-1}$. 鄱阳湖在近 50 年来水情不断恶化, 一再出现超历史最高洪水位, 洪涝灾害愈演愈烈, 其原因何在? 为此, 笔者统计分析了鄱阳湖 流域近 50 年来的降水资料, 并就各典型年入湖洪水特征作一概略比较 (表 2). 统计分析结果 表明鄱阳湖流域近 50 年来的汛期降水量无增多趋势, 说明鄱阳湖洪水位升高并非是由于流域 内降水增多、赣江等五大入湖河流汛期来水量增加所致. 正如表 2 中所列, 以 1954、1995 年两 个特大洪水年作为典型年, 就其最大入湖流量、峰前洪水总量进行比较就可以看出: 1954 年最 大入湖流量为 $43430 \mathrm{~m}^{3} \mathrm{~s}^{-1}$, 峰前洪水总量为 $216 \times 10^{8} \mathrm{~m}^{3} ; 1995$ 年最大入湖流量为 $36100 \mathrm{~m}^{3} \mathrm{~s}^{-1}$, 峰前洪水总量为 $146 \times 10^{8} \mathrm{~m}^{3}$. 无论是最大入湖流量, 抑或是峰前洪水总量, 1995 年均明显小于 1954 年, 然而 1954 年的最高洪水位为 $21.71 \mathrm{~m}, 1995$ 年的最高洪水位为 $21.78 \mathrm{~m}, 1995$ 年与 1954 年相比却高出 $0.07 \mathrm{~m}$. 若再以 1954 年与 1998 年的最大出湖流量相比 较, 1954 年的最大出湖流量为 $22300 \mathrm{~m}^{3} \mathrm{~s}^{-1}, 1998$ 年为 $31900 \mathrm{~m}^{3} \mathrm{~s}^{-1}, 1998$ 年比 1954 年大 $9600 \mathrm{~m}^{3} \mathrm{~s}^{-1}$, 而 1998 年的最高洪水位却高出 1954 年 $0.71 \mathrm{~m}$, 前后对比, 反差也十分明显.

表 2 都昌站具型年洪水位特征统计*

Tab.2 Statistics on the flood character in certain typical years, Duchang station

\begin{tabular}{ccccccc}
\hline 典型年 & $Q_{\max } / \mathrm{m}^{3} \mathrm{~s}^{-1}$ & $W / 10^{8} \mathrm{~m}^{3}$ & $H_{\max } / \mathrm{m}$ & $N_{19}$ & $N_{20}$ & $M_{21}$ \\
\hline 1954 & 43430 & 216 & 21.71 & 120 & 94 & 45 \\
1962 & 32600 & 133 & 20.15 & 26 & 8 & - \\
1973 & 35600 & 126 & 20.81 & 32 & 21 & - \\
1983 & 29300 & 141 & 21.58 & 47 & 26 & 13 \\
1995 & 36100 & 146 & 21.78 & 35 & 26 & 17 \\
\hline
\end{tabular}

* $Q_{\max }$ 为入湖最大流量; $W$ 为峰前洪水总量; $N_{19}, N_{20}, N_{21}$ 为日平均水位超过 $19 \mathrm{~m}, 20 \mathrm{~m}, 21 \mathrm{~m}$ 的持续天数.

与此同时,笔者又分析研究了鄱阳湖泥沙沉积现状. 据观测资料, 鄱阳湖湖水多年平均含 沙量为 $66.1 \mathrm{gm}^{-3}$, 是长江中下游过水性湖泊中泥沙含量较小者. 据统计, 多年平均入湖泥沙为 $1604.2 \times 10^{4} \mathrm{~m}^{3}$, 出湖泥沙为 $736.5 \times 10^{4} \mathrm{~m}^{3}$, 多年平均泥沙淤积量为 $867.7 \times 10^{4} \mathrm{~m}^{3}$, 全湖平均 泥沙淤积速率约为 $2.6 \mathrm{~mm} \cdot \mathrm{a}^{-1[5]}$. 这说明泥沙沉积并非是引起鄱阳湖洪水位不断抬升的主导 因素。

通过以上对比分析, 答案已十分清楚, 引起鄱阳湖水情日益恶化和洪水位不断抬升的最主 要原因, 显然是由于该湖的大量围旺以及由此而导致湖泊面积、容积的急剧缩小和调蓄功能的 严重衰退. 据分析计算, 鄱阳湖因围圼而损失的湖泊容积达 $80 \times 10^{8} \mathrm{~m}^{3}$, 这一数字大致相当于 目前湖泊容积的 $50 \%$ 左右. 由于湖泊容积锐减, 调蓄功能下降, 即使是在同等入湖流量的情况 
下, 其导致洪水位的抬高以及高水位持续历时之延长已是必然.

\section{3 围圼对鄱阳湖洪水位影响的定量计算与分析}

为了能定量揭示围旺对翻阳湖洪水位的影响, 采用基于湖泊水量平衡方程的“典型年交叉 调洪演算方法”,计算有关典型年洪水出现在不同年份围崖背景下的洪水过程。

湖泊短时段水量平衡(忽略微量项)方程为：

$$
\Delta W=\Delta H \cdot \bar{F}=\left(\bar{Q}_{\curlywedge}-\bar{Q}_{\text {出 }}\right) \cdot \Delta t
$$

式中, $\Delta W$ 为湖泊水量变化; $\Delta H$ 为湖泊水位变化; $\bar{F}$ 为时段内的平均湖泊面积; $\bar{Q}_{\lambda} 、 \bar{Q}_{\text {出 }}$ 为时 段内的平均入、出湖流量; $\Delta t$ 为时段长度.

由 (1)变换得到:

$$
H_{2}=H_{1}+\frac{Q_{1}+Q_{2}}{F_{1}+F_{2}} \cdot \Delta t
$$

因鄱阳湖面积大, 调蓄能力较强, 水文惰性明显, 水位的日变幅一般较小, 为适当减少计算 量, 取 $\Delta t=2 \mathrm{~d}$, 得到调洪演覚公式如下:

$$
H_{2}=H_{1}+0.1728 \frac{Q_{1}+Q_{2}}{F_{1}+F_{2}}
$$

式中, $H_{2}$ 为时段末水位的计算值 $(\mathrm{m}) ; H_{1}$ 为时段初水位 $(\mathrm{m}) ; Q_{1} 、 Q_{2}$ 为时段初、末的净入湖 流量 $\left(\mathrm{m}^{3} \mathrm{~s}^{-1}\right) ; F_{1} 、 F_{2}$ 为时段初、末的湖面积 $\left(\mathrm{km}^{2}\right)$.

选取近 50 年内时间分布较均匀出现大洪水或特大洪水的 1954、1962、1973、1983、1995 年 5 个年份为典型年 (表 2). 计算时, 轮流将 5 个典型年中的 1 个典型年作为样本年, 其它 4 个典 型年作为背景年, 利用样本年的洪水过程与背景年的高程 - 面积关系代入 (3)式, 计算出样本 年洪水出现在背景年围旺状态下的洪水位过程, 与样本年实测洪水位过程特征值 (表 2)进行 比较,即可获得样本年洪水在不同围旺背景下的洪水位围旺效应(表 3).

可以看出, 围原不仅使洪水的洪峰水位升高, 还使高水位持续历时延长. 体现在洪水位过 程线上, 即为峰顶升高, 峰体增肥 (图 2). 对于同一洪水, 在不同围圼背景下所出现的洪峰水位. 与高水位持续历时均不相同, 但洪峰水位与高水位持续历时两者之间却有着极为密切的依存 关系, 即洪峰水位越高, 则高水位持续的历时一般也就越长, 故分析围是对洪水位的影响, 只着 重分析洪峰水位的围崖效应.

由表 4 可见, 不同形态洪水受围暍影响的程度也不同, 在所列的 5 个典型年中, 以 1995 年 洪水的围旺效应最大,1954 年次之, 1973 年及 1962 年相对较小: 总的趋势是较大洪水的围星 效应大于较小洪水的围星效应. 考虑到 1954 年洪水的量级较 1995 年的洪水更高, 且翻阳湖区 绝大多数防洪工程是按防御 1954 年型洪水标准进行设计施工的, 湖区各地防洪规划与防洪预 案的制订也大部分是以 1954 年洪水为主要对象, 因此,下面以 1954 年洪水为例, 进一步分析 围旺对洪水位的影响.

从表 2、表 3 和图 3 可以看出, 日平均水位在 $19 \mathrm{~m} 、 20 \mathrm{~m} 、 21 \mathrm{~m}$ 以上的各级别水位持续天数 增加值 (效应值) 中, $19 \mathrm{~m} 、 20 \mathrm{~m}$ 两个级别的数值相近, 而 $21 \mathrm{~m}$ 以上这一级别的增加值远大于 $19 \mathrm{~m}$ 和 $20 \mathrm{~m}$ 的两个级别, 说明围旺对高水位的影响远大于对低水位的影响. 建国以来, 鄱阳湖 区水情不断恶化, 高水位持续历时延长, 造成圩区洪涝灾害日益频繁, 防洪负担越来越重, 其原 
因就在于此。

表 3 典型年洪水在不同围悬背景下洪水位特征值的计算结果

Tab.3 Calculated flood characters in typical food years under different reclamation backgrounds

\begin{tabular}{|c|c|c|c|c|c|}
\hline 样本年 & 背景年 & 最高水位/m & $\begin{array}{c}19 \mathrm{~m} \text { 以上水位 } \\
\text { 持续时间 } / \mathrm{d}\end{array}$ & $\begin{array}{c}20 \mathrm{~m} \text { 以上水位 } \\
\text { 持续时间 } / \mathrm{d}\end{array}$ & $\begin{array}{c}21 \mathrm{~m} \text { 以上水位 } \\
\text { 持续时间 } / \mathrm{d}\end{array}$ \\
\hline \multirow[t]{5}{*}{1954} & 1962 & 22.10 & 123 & 96 & 68 \\
\hline & 1965 & 22.37 & 129 & 101 & 80 \\
\hline & 1967 & 22.75 & 132 & 105 & 88 \\
\hline & 1973 & 22.96 & 133 & 106 & 90 \\
\hline & 1995 & 23.07 & 134 & 109 & 91 \\
\hline \multirow[t]{5}{*}{1962} & 1954 & 19.86 & 22 & - & - \\
\hline & 1965 & 20.31 & 28 & 13 & - \\
\hline & 1967 & 20.61 & 31 & 17 & - \\
\hline & 1973 & 20.73 & 31 & 17 & - \\
\hline & 1995 & 20.83 & 32 & 18 & - \\
\hline \multirow[t]{5}{*}{1973} & 1954 & 20.17 & 29 & 13 & - \\
\hline & 1962 & 20.28 & 29 & 15 & - \\
\hline & 1965 & 20.47 & 31 & 17 & - \\
\hline & 1967 & 20.72 & 32 & 20 & - \\
\hline & 1995 & 20.90 . & 33 & 22 & - \\
\hline \multirow{6}{*}{1983} & 1954 & 20.52 & 29 & 14 & - \\
\hline & 1962 & 20.83 & 33 & 19 & - \\
\hline & 1965 & 21.07 & 40 & 22 & 2 \\
\hline & 1967 & 21.39 & 45 & 25 & 11 \\
\hline & 1973 & 21.49 & 45 & 25 & 12 \\
\hline & 1995 & 21.61 & 48 & 26 & 13 \\
\hline \multirow[t]{5}{*}{1995} & 1954 & 20.26 & 25 & 11 & - \\
\hline & 1962 & 20.73 & 28 & 17 & - \\
\hline & 1965 & 21.00 & 30 & 20 & 1 \\
\hline & 1967 & 21.45 & 33 & 24 & 13 \\
\hline & 1973 & 21.55 & 33 & 24 & 14 \\
\hline
\end{tabular}

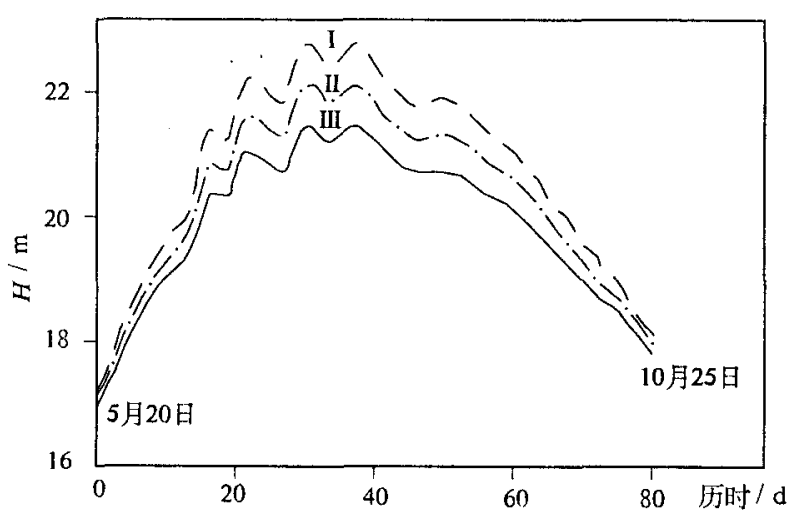

图 21954 年实测洪水位过程及不同围圼规模的围是效应

$\mathrm{I}$ : 围旺 $1400 \mathrm{~km}^{2}$ 时 (1995 年); II : 围悬 $750 \mathrm{~km}^{2}$ 时 (1965 年); III : 实测(1954 年)

Fig. 2 Comparison between the observed and simulated floods under different reclamation backgrounds in typical 1954

在围是面积相近的两个时段内, 后时段围星所造成的水位抬升值大于前时段围星所造成 
的水位抬升值，说明后时段围崖比前时段围旺(即迟围的比早围的)对洪水位的抬升作用更大， 即围是对洪水位的抬升作用随着围垦强度的增加而加大. 例如 1962-1965 年和 1965-1967 年, 䧽阳湖分别围是 $290 \mathrm{~km}^{2}$ 和 $340 \mathrm{~km}^{2}$, 分别使 1954 年洪水的洪峰水位升高 $0.27 \mathrm{~m}$ 和 $0.38 \mathrm{~m}$; 又如 1954-1962 年和 1965-1973 年, 分别围旺 $440 \mathrm{~km}^{2}$ 和 $496 \mathrm{~km}^{2}$, 分别使 1954 年型 洪水的洪峰水位升高 $0.39 \mathrm{~m}$ 和 $0.59 \mathrm{~m}$.

表 4 各典型年洪峰水位围星效应的计算结果

单位: $m$

Tab. 4 Calculated flood level changes in certain typical years

\begin{tabular}{ccccccc}
\hline 背景年段 & $1954-1962$ & $1962-1965$ & $1965-1967$ & $1967-1973$ & $1973-1995$ & $1954-1995$ \\
\hline 1954 & 0.39 & 0.27 & 0.38 & 0.21 & 0.11 & 1.36 \\
1962 & 0.29 & 0.16 & 0.30 & 0.12 & 0.10 & 0.97 \\
1973 & 0.11 & 0.19 & 0.25 & 0.09 & 0.09 & 0.73 \\
1983 & 0.31 & 0.24 & 0.32 & 0.10 & 0.12 & 1.09 \\
1995 & 0.44 & 0.30 & 0.45 & 0.10 & 0.23 & 1.52 \\
\hline
\end{tabular}

从图 3 中可清楚地看出, 曲线 3 的位置远 远高于曲线 1 , 说明在现状基础上若再进行围 星, 要比在 1954 年基础上作相同面积的围星 对洪水的影响要大得多 (洪峰水位要高得多、 高水位持续时间要长得多). 曲线 $1 、 2$ 均为凹 型曲线, 表明洪峰水位的抬升速度(单位围圼 面积造成的洪峰水位上升量) 随围是面积的加 大而增大.

造成上述现象的原因, 主要是鄱阳湖的湖 盆具有天然比降, 洲滩地势由四周向湖心、由 上游向下游逐渐降低, 而围是则是具有自湖四 周的高位滩地逐渐向湖中的中位滩地或低位 滩地延伸、相继筑堤围垸之时空变化规律, 在 围是面积相同的情况下, 后围的地区比先围的 地区所占据的湖泊容积显然要大得多, 对湖泊 调蓄能力的削减作用相应也就大得多:

从表 5 可以看出在目前围星规模情况下, 如果各典型年洪水再现, 其相应出现的洪峰水 位要比当年实测值显著增高、高水位持续历时 也相应延长. 在 5 个典型年洪水中, 洪水以 1954 年最大, 1995 年洪水次之, 1983 年洪水居 中, 1962 年洪水最小, 1973 年洪水次小. 实测

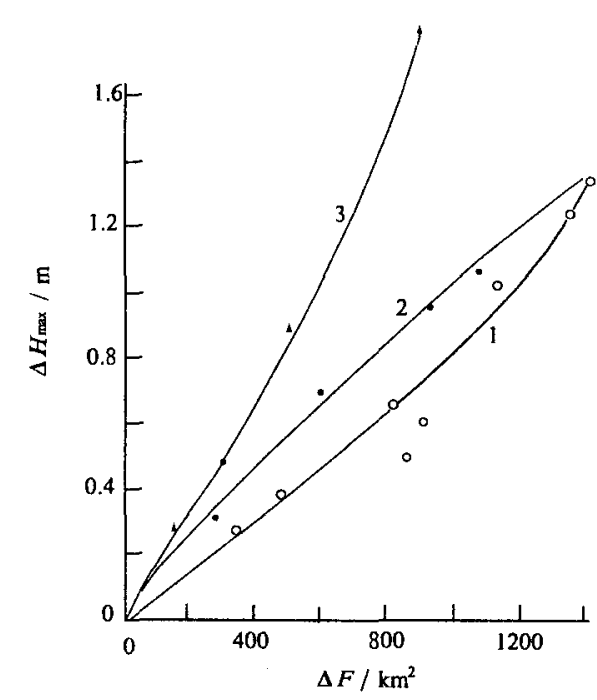

图 31954 年型洪水洪峰水位围是、退崖效应

1. 围圼使湖水位抬高;

2. 退圼使湖水位爀低;

3. 在当前围圼现状基础

上再围圼使湖水位抬高

Fig. 3 The 1954-type observed and calculated

flood processes showing the rectlamation, de-reclamation effects

洪峰水位则以 1995 年的 $21.78 \mathrm{~m}$ 最高, 1954 年的 $21.71 \mathrm{~m}$ 次之. 但是, 在 1995 年的围旺现状 条件下, 若 1954 年型的洪水再现, 经计算其洪峰水位可达 $23.07 \mathrm{~m}$, 比当年实测值要高出 $1.36 \mathrm{~m}$, 比 1995 实测洪峰水位还高 $1.29 \mathrm{~m}$; 再以典型年中洪水来量最小的 1962 年为例, 洪峰 
水位也将达到 $20.83 \mathrm{~m}$, 比实测值高出 $0.68 \mathrm{~m}$. 大规模围星所引起的洪水之害, 由此不难想见. 目前, 湖区防洪工程的新建与改建、城镇防洪工程规划的制订, 仍应以 1954 年型洪水为防御对 象(或设计标准), 但是不可忽视大规模围星等人为因素影响的现状.

表 5 各舆型年洪水在当前同垦状态下的相应洪水位计算值与实测值比较

Tab.5 The calculated and observed flood characters of certain typical flood years under present conditions

\begin{tabular}{|c|c|c|c|c|c|c|c|c|c|c|c|c|}
\hline \multirow[t]{2}{*}{ 骨型年 } & \multicolumn{3}{|c|}{ 最简水位 $(\mathrm{m})$} & \multicolumn{3}{|c|}{$\begin{array}{c}19 \mathrm{~m} \text { 以上水位 } \\
\text { 持续时间 } / \mathrm{d}\end{array}$} & \multicolumn{3}{|c|}{$\begin{array}{c}20 \mathrm{~m} \text { 以上水位 } \\
\text { 持续时间 } / \mathrm{d}\end{array}$} & \multicolumn{3}{|c|}{$\begin{array}{c}21 \mathrm{~m} \text { 以上水位 } \\
\text { 持续时间 } / \mathrm{d}\end{array}$} \\
\hline & 实测 & 计算 & 种高 & 实测 & 计算 & 增加 & 实测 & 计算 & 增加 & 实测 & 计算 & 增加 \\
\hline 1954 & 21.71 & 23.07 & 1.36 & 120 & 134 & 14 & 94 & 109 & 15 & 45 & 91 & 46 \\
\hline 1962 & 20.15 & 20.83 & 0.68 & 26 & 32 & 6 & 8 & 18 & 10 & - & - & - \\
\hline 1973 & 20.81 & 20.90 & 0.09 & 32 & 33 & 1 & 21 & 22 & 1 & - & - & - \\
\hline 1983 & 21.58 & 21.61 & 0.03 & 47 & 48 & 1 & 26 & 26 & 0 & 13 & 13 & 0 \\
\hline 1995 & 21.78 & 21.78 & - & 35 & 35 & - & 26 & 26 & - & 17 & 17 & - \\
\hline
\end{tabular}

\section{4 在围垦现状条件下的再围层与退垦对洪水位影响的估算}

今后鄱阳湖圩区及滩地资源的开发利用存在着两种可能的途径. 其一, 在目前的围堅现状 基础上, 继续筑堤建圩, 不断扩大围层规模; 其二, 鉴于围旺已引起湖泊水情不断恶化、洪水位 抬升、防洪形势严峻, 对部分坶区采取退是还湖的果断措施. 为此, 对这两种可能的不同情况在 目前的湖㿽形态现状下对洪水位的影响进行了初步估算(表 6).

装 61954 年型洪水在围圼现状基础上再围晊(退圼)条件下的洪峰水位变化 ${ }^{*}$

Tab. 6 The calculated flood peak changes after further reclamation/de-reclamcation based on 1954-type flood precesses under present situation

\begin{tabular}{cccccc}
\hline 目(退)星面积 $/ \mathrm{km}^{2}$ & $150 \mid-150$ & $300 \mid-300$ & $500 \mid-500$ & $900 \mid-900$ & $1100 \mid-1100$ \\
\hline 淇峰水位 $/ \mathrm{m}$ & $23.35 \mid 22.84$ & $23.56 \mid 22.66$ & $23.97 \mid 22.46$ & $24.87 \mid 22.11$ & $25.32 \mid 21.94$ \\
$\Delta H_{\max } / \mathrm{m}$ & $0.28 \mid-0.23$ & $0.49 \mid-0.41$ & $0.90 \mid-0.61$ & $1.80 \mid-0.96$ & $2.25 \mid-1.13$ \\
\hline
\end{tabular}

* $\Delta H_{\max }$ 系指在现状基础上逃一步国圼(退䃌)条件下洪峰水位的上升(下降)变幅.

从上表 6 中所列数据及图 3 中曲线 1,3 位置的差异, 足以说明在现状基础上如果再进行 围旺, 则必将加速鄱阳湖业已不断恶化的水情演变过程, 其危害将远远大于过去. 以 1966 年建 康山圩堤为例, 当时大约使 1954 年型洪水的洪峰水位抬高 $0.4 \mathrm{~m}$; 若现在再围建一个与康山圩 等同面积的坶子, 1954 年型洪水的洪峰水位将在 1995 年洪峰水位基础上再抬高 $1.82 \mathrm{~m}$, 达到 $23.6 \mathrm{~m}$, 超过了目前大部分圩堤的堤顶高程, 其严重后果可想而知. 据此分析计算, 作者认为今 后鄱阳湖应当严禁盲目围旺, 并采取相应的管理措施.与上述再围旺的情况相反, 如果在目前 围星现状条件下, 采取退旺的措施, 将一部分圩区实施退田还湖, 则必将使鄱阳湖的水情有所 改善,调蓄功能增强, 洪峰水位降低(表 6), 从而带来正面效应.

总之, 退田还湖是改善鄱阳湖水情、削减洪峰水位行之有效的一种措施，退旺的面积愈大, 其削减洪峰水位的效应愈显著. 诚然, 退田还湖不仅要考虑到湖泊的水情, 还涉及到圩区社会 经济的发展现状和广大群众及财产的转移安置等多个方面, 问题复杂, 决不可草率行束. 


\title{
参 考 文 献
}

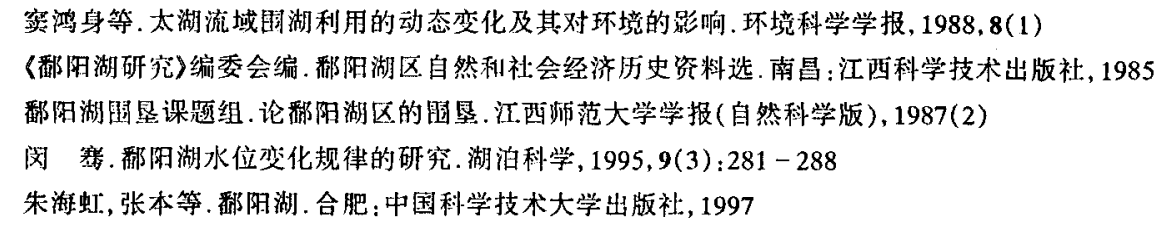

\section{Impacts of Reclamation on the Flood Regime in Poyang Lake and Countermeasures}

\author{
DOU Hongsheng ${ }^{1} \quad$ MING Qian ${ }^{2} \quad$ SHI Fuxiang ${ }^{1}$ \\ (Nanjing Institute of Geography \& Limnology, Chinese Academy of Sciences. Nanjing 210008; \\ 2: Duchang Evaporation Observation Station of Jiangxi Province, Duchang 332600)
}

\begin{abstract}
Poyang Lake is the largest freshwater lake in China with a catchment area of $162000 \mathrm{~km}^{2}$. The only outlet to the Changjiang River is at Hukou. The flood regimes in the lake are mainly controlled by the Changjiang River and the 5 tributaries to the lake.

The reclamation in the lake area may be traced back to the Song Dynasty. The benefits of reclamation to mankind were inevitably hampered due to the frequent natural flooding. It was estimated that an area of $15.8 \mathrm{~km}^{2}$ had been reclaimed before 1949 , among which the standards of many dykes were too low to resist heavy flooding. After 1949, the economic growth as well the urgency for eliminating popular snail fever in the lake beach triggered the large-scale reclamation movement around the lake. Up to 1995, statistics show that a total area of $1466.9 \mathrm{~km}^{2}$ has been reclaimed, which brought a series of unfavorable influences on the flood regimes of the lake, such as: (1) the shrinkage of lake area and capacities, (2) the deterioration of flood regulating and functioning, and (3) the ascending of peak floods and corresponding frequencies.

The impacts of reclamation on the flood regime of Poyang Lake are analyzed. Five representative flood years, i.e., 1954, 1962, 1976, 1983 and 1995 are selected.as backgrounds for estimation. Comparisons are made between the calculated and observed flood characters of certain typical flood years under present reclamation conditions. Furthermore, the supposing flood peak changes conditioning future reclamation/de-reclamation based on 1954-type flood processes under present situation are given. The more de-reclamation, the more will flood regime be alleviated.
\end{abstract}

Key Words Poyang Lake, reclamation, flood disaster, countermeasures 